\title{
Economic-engineering design for logistics infrastructure routing
}

\author{
Weerapol Namboonruang ${ }^{1 \mathrm{a}}$, Noppadon Amdee $^{2}$, Nutthanun Suphadon ${ }^{3}$ and Boontham Krisonsri ${ }^{4}$ \\ ${ }^{1}$ Department of Civil Technology and Architecture, Faculty of Industrial Technology, Muban Chombueng Rajabhat University, MCRU \\ 70150, Thailand \\ ${ }^{2}$ Department of Manufacturing Technology, Faculty of Industrial Technology, Muban Chombueng Rajabhat University, MCRU 70150 , \\ Thailand \\ ${ }^{3}$ National Metal and Materials Technology Center 12120, Thailand \\ ${ }^{4}$ Bureau of Location and Design, Department of Highway, Ministry of Transport 10400, Thailand
}

\begin{abstract}
The existing transport route starting from Lamchabang seaport - Bangkok - Nakhonpathom province was studied in the terms of logistic and supply chain. This work, the new route starting from Ratchaburi-SuanphuangChong-Tagobon border will be studied which will be promoted to be the new transportation and transfer of goods route from Thailand to Myanmar via Chong-Tagobon border checkpoint, Ratchaburi province to the Highway No.9 of Myanmar. The study focuses on the possibility of infrastructure and logistic system of Ratchaburi province selected as the center of goods distribution. There are two optional routes that are studied. The first route starts from km. $0+0.000-\mathrm{km} .91+174$ with a total distance of 91.174 kilometers. The second route starts from $\mathrm{km} .0+0.000-$ km. $93+219$ with a total distance of 93.219 kilometers. For the analysis in format of engineering and economics found that Route No.1 is more appropriate to use as the transport route for connecting the economics between Thailand-Myanmar borders. The value of the investment in logistic infrastructure (road) is approximately 3,612 million baths.
\end{abstract}

\section{Introduction}

In 2015, Thailand and the nine other neighboring countries have joined the AEC (Asean Economics Community). Then, it is necessary to study routes that can be linked to the benefits of trade and economic development together. Chong - Tagobon, Ratchaburi province is one of area where has the border line with Myanmar which is currently used as barter, labor checkpoint and the western border trade of Thailand. Also, it is located at the main highway network (No.4) and Asia highway No.2(AH2).

The distance from the main highway network is just $90 \mathrm{~km}$. Also, this route is connected to the highway No.9 of Myanmar where can be used as alternative route to the Dawei deep seaport. Although the expanded infrastructure is just part of managing congestion, especially the expansion of the road, which requires the state's fiscal austerity measures and need to be carefully considered [1]. The regulatory and legal economy is a priority for the development of infrastructure effectively and could lead to transport efficiency, as well as control legislation. Management of the economic activity [2] was developed and deployed in the field of control of state infrastructure. This could be a study of the economic dimension of transport and mechanisms related to the impact of regulatory measures (on the development of transport infrastructure [3-11]. Furthermore, it also

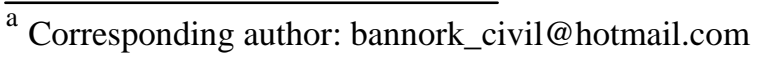

covers the financing of efficient transport infrastructure [12]. For the development of country, if Chong-Tagobon could be developed as the main economic border, it would be one of the most important the economic border of Thailand.

\section{Methodology}

\subsection{Design details of logistic infrastructure using Asphalt Institute Method}

The asphalt road structure can be designed by various ways which are widely separated into 2 methods: using experience and analysis. The design using Asphalt Institute Method Vol.8 (1970) [13,14] is one of the design using experience method which has been selected by the department of highway to design asphalt road for 25 years because it is convenient, fast, and non-complex testing method. Therefore, this guide is designed to interesting people and officials who are responsible for the structural design of asphalt to understanding of the principles and processes of pavement roads in Thailand. The structural design of the pavement road by the Asphalt Institute No. 8 is experiential method which brings information taken from the results of the road testing by following AASHTO Road Test, WASHO Road Test, British Road Test and real experience to analyze the relationship between all factors and the depth of 
pavement. Materials in pavement layer following this relationship will be asphalt material called the Full-Depth Asphalt Thickness $\left(\mathrm{T}_{\mathrm{A}}\right)$.

However, the cost of Full-Depth Asphalt Pavement is high and cannot be replaced by any local materials. Then, the Asphalt institute has set the constant parameter called the substitution ratio to convert the depth of asphalt to the depth of the replaced material which allows designer can select other cheaper local materials and design the pavement structure as multilayers. According to the study found that the compressive force in the pavement structure relates to the depth as shown in Fig.1. It clearly shows that the compressive force shows the maximum value at the area of the road surface and decreases with increasing the depth. Therefore, to reduce the construction cost, it is often designed using the best quality materials close to the road surface area and inferior quality materials used in deeper layers.

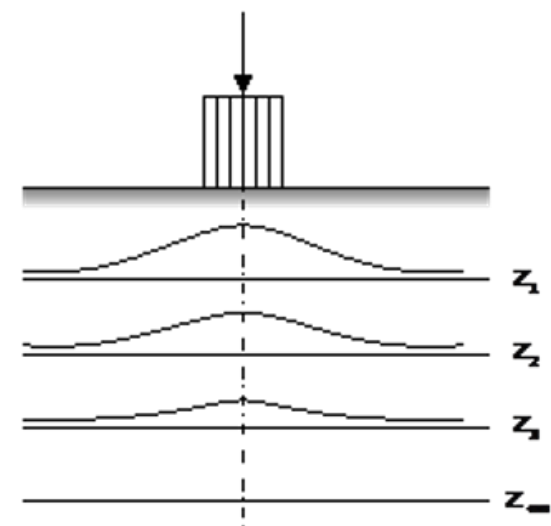

Figure 1. Show the vertical force distribution from vehicle weight at different depths[15].

\subsection{Element of design}

The primary information used to design of the asphalt road construction following the Asphalt Institute method No.8 are the traffic volume and the load bearing of the soil foundation which are measured in terms of the design Traffic Number (DTN) and CBR, Plate Bearing k-value or R-value, respectively. Details of these values will be explained in Chapter 2.3, 2.4 and 2.5. In addition, the ratio of the strength of materials used in each layer (Substitution Ratios) is another important factor that is used to convert the thickness of full depth asphalt pavement road as a multi structure layer by substitution ratios.

\subsection{Traffic volume}

Traffic volume used to design following the asphalt institute No.8 is used in the term of design traffic number (DTN) which is the average number of trips per day, the number of vehicles with axle weight standards equivalent to 18,000 pounds which are converted from different car types and axle weights expected to use in traffic lane in all designed duration. To evaluate the DTN value is dependent on various variables such as duration, number of the heavy trucks and the increasing rate of number of heavy trucks etc.

\subsection{The strength of the soil foundation}

The design of pavement by the Asphalt Institute No.8. [16,17] presents that factors related to the strength of the soil are shown in the form of CBR, Plate Bearing $\mathrm{K}$-value, or $\mathrm{R}$ value. However, comparison to all factors, CBR is the most widely used because it is fast and convenient method. Then the department of highway has selected the percentage of CBR method to design the pavement structure following Asphalt Institute No.8. $[16,17]$. In addition, this work will explain only the CBR testing method.

\subsection{Design of asphalt thickness}

As mentioned earlier, the designed thickness is the Full Depth Asphalt Thickness $\left(\mathrm{T}_{\mathrm{A}}\right)$ and then converted to the multi-layer thickness. This thickness design according to the Asphalt Institute No. 8 can be easily calculated which there are only two important parameters related such as DTN and the strength of the soil. Full Depth Asphalt Thickness $\left(\mathrm{T}_{\mathrm{A}}\right)$ can be obtained by using basic equations developed from experiments or Monograph generated from the above equation. The basic equations used in the design are comprised of three equations as shown in equation (1)-(3). It is dependent on the designer that what information they have. For example, if selects the strength of soil foundation in term of percentage of CBR, equation 1 will be chosen. If there is R-value, equation (2) or (3) can be selected depending on DTN value and so on.

$$
\mathrm{T}_{\mathrm{A}}=\frac{9.19+3.97 \log \mathrm{DTN}}{(\mathrm{CBR})^{0.4}}
$$

$\mathrm{T}_{\mathrm{A}}=6.37+2.75 \log \mathrm{DTN}-0.0893 \mathrm{DTN}^{0.119}(\mathrm{R}-12)$

$$
\mathrm{T}_{\mathrm{A}}=6.37+2.75 \log \mathrm{DTN}-0.117 \mathrm{DTN}^{0.0279}(\mathrm{R}-12)
$$

When: $\mathrm{T}_{\mathrm{A}}=$ Thickness of asphalt layer

\subsection{Research Tools}

The analysis and engineering design are following by standards of ASTM, ASSHTO, Asphalt Institute Method, the Department of Highways, Ministry of Transport and geographic information systems and engineering information. The data are collected from engineering property testing as well as the use of geographic information systems for engineering design and analysis. In this study, results are analyzed using data from engineering testing and geographic information systems. An engineering design for the infrastructure and the laboratory tests are processing by the computer as a tool for analysis, including statistics related to the test such as Mean values and a percentage and so on. 


\section{Results and Discussions}

\subsection{Topographic and Route Survey}

Survey work and the design of road construction starting from Ratchaburi province to the border of Thailand and Myanmar is the construction project promoted for the border business. The beginning point starts at the conjunction of the highway No.4 at km.102+713 through Ratchaburi capital district, Chombuang district and to meet the border of Thailand Myanmar at Suan-Phung district. The total distance is approximately $90 \mathrm{~km}$. Due to the initial design, data are only imported form Geographic Information Systems Engineering which comprised of the satellite images and contour line as shown in Figure 2 and 3.

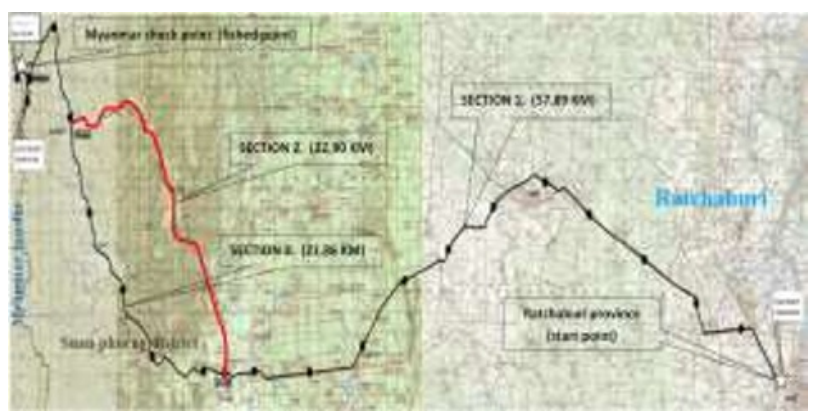

Figure 2. Map of the project line

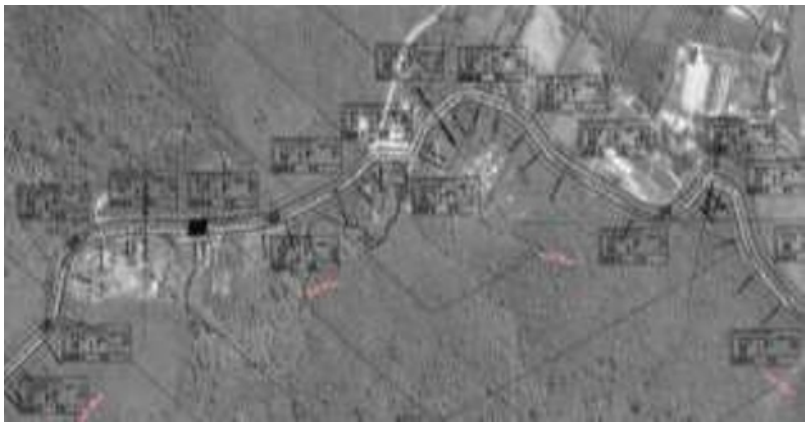

Figure 3. Show the satellite geographic image and contour line to apply for the project design

\subsection{Traffic volume survey}

By counting the traffic volume of the department of highway in 2015 on the Highway No. 3208, mine is the road that overlaps with the studied route project. Then, a total of three points are inspected. First point is at $\mathrm{km} .3+000$ which has the ADT value of 12,422 vehicles per day. For second point $(\mathrm{km} .19+714)$ and third point $(\mathrm{km} .51+823)$, the ADT values are 6,755 and 5,893 vehicles per day, respectively.

\subsection{Detail of intersection design}

Typically, the type of intersections in different places often varies according to the amount of traffic, the direction of turns, and the complexity of the traffic flow. For example, Intersections, where have the traffic volume on the secondary road less than 500 vehicles per day, it would take the typical intersections which is often used to a general link. If inter section has a traffic volume of more than 1,000 vehicles per day, it would be considerably managed the channelization at the conjunction and the traffic light would be considerably used in case a traffic volume of more than 1,500 vehicles per day or other emergency case, for example, the statistics of accidents occurring at intersections that are relatively high and so on. Therefore, the design of intersections at the same level will consider as a type of traffic lights and no traffic lights. Consideration of the various elements mentioned above will refer to the provisions of the HCM (TRB) as the first priority and the design of shape of the geometry will follow the standards of the Department of Rural Roads together with the standard by AASHTO-A policy on Geometric Design of Highway and Streets, 2004 [15] and the visible safety range in other cases can be designed by following to the same standard.

\subsection{Analysis of route selection feasibility}

The study will start by selecting the most appropriate route. The study will be based on two main factors for instance economics and engineering. In figure 4 , there are 2 routes which are compared. In selecting the appropriate route, the data of section 3 of route alternative No.1 and the section 2 of route alternative No. 2 are compared since they are difference between the two alternatives.

Table 1 shows the comparison of alternative route No. $1(\mathrm{~km} .0+0.000-\mathrm{km} .91+174)$. and No.2 (km.0+0.000 $-\mathrm{km} .93+219)$. It is found that the first alternative's distance is shorter than the second alternative route about 2.04 kilometers and it is considered that it shows a better geometry because it has less curve which is more convenient and safer for the driver. However, by measuring from both routes have nearly an equal number of vertical curves, the second alternative route has a greater slope and it cuts through the water with a longer distance. It is measured that the total bridge length is 360 meters and the route is more winding and steep. Consideration by economic analysis in construction details, it found that the stability of the road and the prevention of erosion are quite major factor resulting on higher cost of construction of the route No.2. By comparison of engineering factors, it clearly shows that route No.1 is suitable to use as the logistic route in this study.

Table 1. Show the comparison of engineering factors for route No.1 (section 3) and route No.2 (section 2)

\begin{tabular}{|c|c|c|c|c|}
\hline Route No. & $\begin{array}{c}\text { Horizontal } \\
\text { curve }(\mathrm{N})\end{array}$ & $\begin{array}{c}\text { Vertical } \\
\text { curve }(\mathrm{N})\end{array}$ & $\begin{array}{c}\text { Slope } \\
(\%)\end{array}$ & $\begin{array}{c}\text { Bridge } \\
(\mathrm{m} .)\end{array}$ \\
\hline 1 (Section 3) & 60 & 15 & 6.2 & 240 \\
\hline 2 (Section 2) & 135 & 14 & 11.1 & 360 \\
\hline
\end{tabular}

Table 2. and Figure 2 show a comparison of construction costs of logistic infrastructure designed by using material from Ratchaburi sources. For example, the cost of soil reclamation including transportation, operation, profit and tax is about 110 baths per cubic meter and so on. Therefore, comparing the cost of all materials used for road construction, it is found that the 
routes No.2 show a higher value which makes the cost of overall construction projects is also high. Then, if considers only the investment in infrastructure, it can be concluded that the route No.1 is more appropriate than route No.2 which would be used as logistic route from Laemchabang seaport-Nakhonpathom-Highway No.4Ratchaburi- Jedeehak intersection- Highway No. 3087 and Chong-Takobon border checkpoint.

Table 2 shows the cost of construction infrastructure, starting from Khoa-Ngu intersection $(\mathrm{km} \quad 0+0.000$ intersect with Highway No.4, AH2) along the route No.1. to Chong-Takobon checkpoint (km 91.+174) with overall distance of 91.174 kilometers. The total costs calculated only the road and the bridge construction based on economic investment from the government is 3,612 million baths.

Table 2. Show the cost of the logistic infrastructure investment compared between the route No.1 (section 3) and route No.2 (section 2)

\begin{tabular}{|c|c|c|c|}
\hline Route No. & $\begin{array}{c}\text { Cost of } \\
\text { Pavement } \\
\text { (average 40 } \\
\text { million } \\
\text { baths/kilometer) }\end{array}$ & $\begin{array}{c}\text { Cost of bridge } \\
\text { (average } \\
320,000 \\
\text { baths/meter) }\end{array}$ & $\begin{array}{c}\text { Total } \\
\text { (million } \\
\text { baths) }\end{array}$ \\
\hline 1 (section 3) & 874.40 & 7.68 & 882.08 \\
\hline 2 (section 2) & 956.00 & 11.52 & 967.52 \\
\hline $\begin{array}{l}\text { Route No 1. (km.0+0.000-91+174) } \\
\text { distance of 91.174 km. }\end{array}$ & $3,612.00$ \\
\hline $\begin{array}{l}\text { Route No 2. }(\mathrm{km} .0+0.000-93.219) \\
\text { distance of } 93.219 \mathrm{~km} .\end{array}$ & Total & $3,693.00$ \\
\hline
\end{tabular}

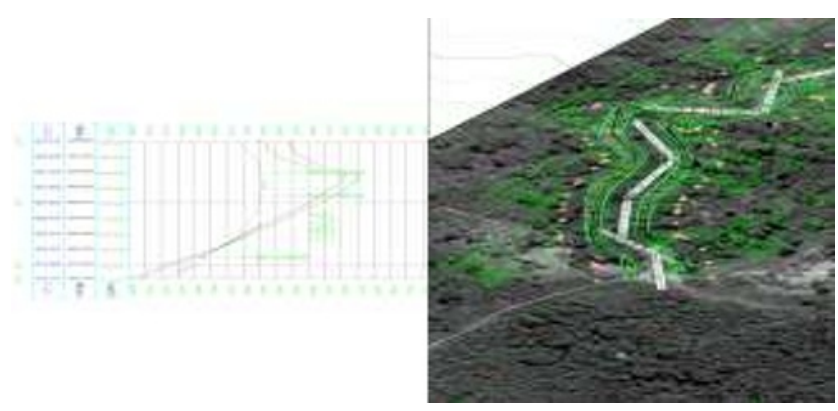

Figure 4. Show the engineering profile design of infrastructure on the Chong-Takobon border (Thailand side) and the border where connecting to the Highway No. 9. (Myanmar side)

\subsection{The selection of the routes by the project analysis}

According to study above, the appropriate route to use for logistic transportation considered by engineering infrastructure factor is the route No.1. Next, environmental effects that will be analyzed and considered the suitability to start the construction process including the implementation of the project in the next step. By counting the traffic volume of Department of Highway, it is found that the maximum traffic volumes is 12,422 vehicles per day, and by the standards of the Department of Highways, the road should be designed as four lanes (special class). For crossing the natural channel, the short bridge will be used and for mountain section, the suitable structure design will be considered to fit with the shape of the terrain which might cut deep or fill high. Moreover, the design will add special lanes for trucks to climb steep slopes (Climbing Lane), so fourlane roads with lane width of 3.50 meters and shoulder lane width of 2.50 meters are designed. Including the middle island with Painted Median type of 1.60 meters in width is used. In addition, for the area, where accesses to the intersection, the middle mountain is designed as a raised is mountain (raised median) of 4.60 meters in width because it is convenience and safety for vehicles waiting to turn as shown in Figure 5. For the road at the hillside area, the road is designed as 4 lanes with the width of 3.50 meters and shoulder with the width of 2.50 meter. the Barrier is used to divide the traffic direction at the curve area to reduce an accident. The size of the middle island is 1.60 meters in width. The road is also designed to prevent the erosion of the slope. The crosssection picture is shown in Figure 6.

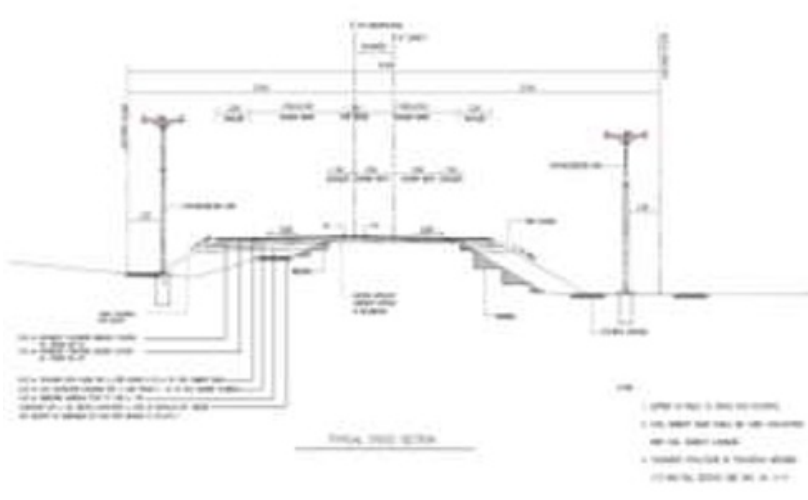

Figure 5. Show the cross-section of the road structure

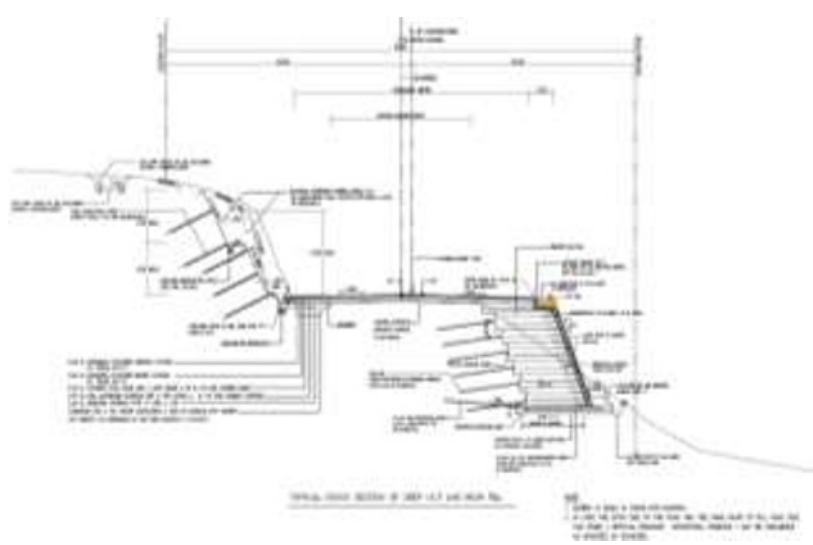

Figure 6. Show the cross-section of the road structure at hillside area

\section{Conclusions}

4.1 Consideration by various factors, it can conclude that road design can be shown in Figure 6 and 7 according to engineering format. For economic analysis, it can be seen that route No.1 is the most appropriate choice with the value of the investment approximately 3,612 million baths. Also, such analysis indicates that if 
the government of Thailand decides to invest in this project, it is not only for Thailand side but also they should consider investing in the important infrastructure in the border area including at Myanmar side to support the connection of the two countries in economy.

4.2 Continuous development format and the link with the project which the government should support. The existing transportation route starting from Lamchabang seaport - Bangkok - Nakhonpathom province was studied in the terms of logistic and supply chain. This work, the extended route Ratchaburi - Suanpuang - Chong Tagobon will be studied. This route will be constructed to be the new transportation and transfer of goods route from Thailand to Myanmar via Chong Tagobon, Ratchaburi province to the highway No.9 of Myanmar. Therefore, to develop this project continuously.

4.3 Develop the tourist attraction widely known as Suan-Phuang district. The development should be appropriate and study and environmental impact including the forest conservation together with the development of preliminary infrastructure. Develop and review, including the clarity of the border open at the level of international cooperation (Thailand - Myanmar).

4.4 The cooperation of the public and private sectors of Thailand - Myanmar in service trucks connection between the dock and the industrial estates of Thailand (Laem-Chabang Industrial Estate - Klong - Toei seaport) and the Myanmar (Dawei industrial estate).

4.5 Economics, social and stability should be discussed and cooperated in the development of Highway No. 9, where is the main transportation of ChongTakobon border to Dawei industrial estate.

\section{References}

1. Grant-Muller, S.M., Xu, M.,Transp. Rev. 34(2), (2014)

2. Posner, R.A., BellJ. Econ. 5(2), (1974)

3. Edwards, H., Berglund, M., European Commission DGVII, (1999)

4. Guasch, J.L.,Hahn,R.W., World Bank Res. Observ.14(1), (1999)

5. Estache, A., World Bank Res. Observ. 16(1), (2001)

6. Harris, C., World Bank Working Paper 5.World Bank Washington, DC.(2003).

7. Fan,S.,Chan-Kang,C., Transp. Policy. 15(5), (2008).

8. Xu,M.,Ceder,A.,Gao,Z.Y.,Guan,W., Transportation, 37(5), (2010)

9. Yang, H.J., Zhang, A.M., J.Transp. Econ. Policy, 46(3), (2012)

10. NERA Economic Consulting., URN09D-596, UK, (2009)

11. Wang, G.M., Gao, Z., Xu, M., Sun, H. J., Transp. Res. Part A. 67, (2014).

12. Helm, D., Thompson, K., J.Transp.Econ.Policy. 25, (1991)

13. AASHTO-A policy on Geometric Design of Highway and Streets, (2004).

14. Thickness Design-Asphalt Pavements for Highways and Streets, The Asphalt Institute, College Park, Md., (1981)
15. Handbook Asphalt Institute Method. Department of Highway, Ministry of Transport. 8, (1970) 